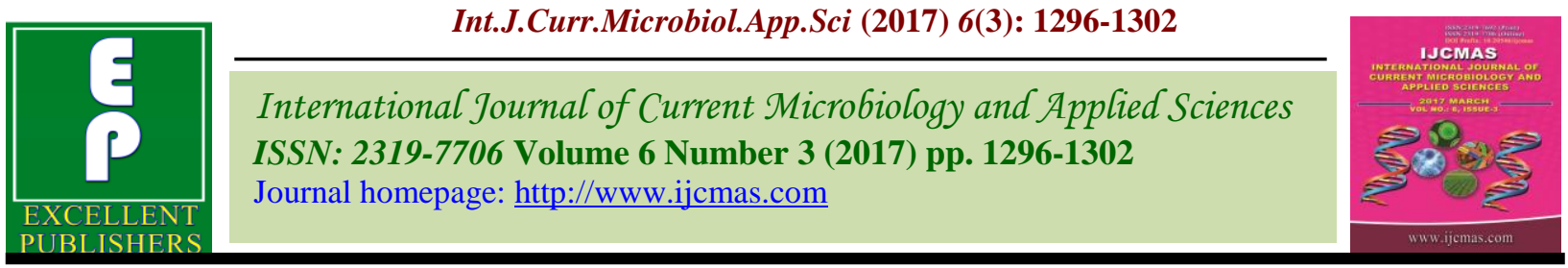

Original Research Article

https://doi.org/10.20546/ijcmas.2017.603.150

\title{
Evaluation of Two Different Lipopolysaccharide Extraction Methods for Purity and Functionality of LPS
}

\author{
D.G. Kalambhe*, N.N. Zade and S.P. Chaudhari \\ Department of Veterinary Public Health, Nagpur Veterinary College, Nagpur, Maharashtra, India \\ *Corresponding author
}

\author{
A B S T R A C T
}

\begin{tabular}{|c|}
\hline Keywords \\
\hline $\begin{array}{l}\text { Lipopolysaccharide, } \\
\text { Methanol- } \\
\text { chloroform, } \\
\text { Proteinase K, } \\
\text { Salmonella } \\
\text { typhimurium. }\end{array}$ \\
\hline Article Info \\
\hline $\begin{array}{l}\text { Accepted: } \\
\text { 20 February } 2017 \\
\text { Available Online: } \\
10 \text { March } 2017\end{array}$ \\
\hline
\end{tabular}

\begin{abstract}
Lipopolysaccharide (LPS) is the major outer membrane component of the Gram negative bacteria, supporting the structural integrity and protecting the membrane from chemical attack. Lipopolysaccharide is pyrogenic, causes endotoxic shock and induces the clinical manifestations of infections. It has the broad applications in cell stimulation experiments which abstract, the basis for studies on the isolation, purification and characterization of LPS. The main problem with LPS purification procedures is the contamination with nucleic acids and proteins which potentially interfere with downstream applications. In this study, we evaluated the Poteinase K-hot-phenol-water extraction method and methanolchloroform method based on the ease of extraction, purity and the functionality of the LPSs isolated from Salmonella Typhimurium. The purity of LPSs was evaluated by silver and Coomassie blue staining of SDS-PAGE and functionality was confirmed by rabbit pyrogen assay. LPS extracted by Proteinase K-hot-phenol-water method demonstrated a typical ladder pattern upon silver staining and no contaminating protein was observed by coomassie blue staining whereas, methanol-chloroform extracted LPS was devoid of such ladder pattern and revealed lighter bands of protein contamination. Parental administration of both purified LPSs resulted in substantial increase of rabbit's body temperature and confirmed the functional activity of both LPSs. Finally it was concluded that the, extraction of LPS by methanol-chloroform method was much easy, less expensive and safer but lacks purity, whereas Proteinase-K-hot phenol water method was tedious, but yielded LPS of high purity.
\end{abstract}

\section{Introduction}

Lipopolysaccharide is a virulent cell membrane component of Gram negative bacteria. It is also a potent activator of immune system capable of triggering cytokine release from cells of different origin. Life threatening diseases as septic shock following infection with Gram negative bacteria is mediated mainly by LPS (Kawaiand Akira, 2010). Lipopolysaccharide (LPS), is a complex structure and is composed of three parts namely, lipid A (immunologic), polysaccharide (role in membrane penetration) and specific $\mathrm{O}$ side chain (antigenicity). Lipid A is highly conserved and exerts the endotoxic activity, while the " $\mathrm{O}$ " antigen is a carbohydrate polymer of repeating oligosaccharides, which differs between species and is responsible for the serological specificity of bacteria (Prescott et $a l$., 2002). LPS causes pathophysiological effects such as fever, leucopenia, leucocytosis etc. (Luderitz et al., 1973) which thus focused 
many studies at its isolation and purification. Numerous methods have been developed for isolation and purification of LPS among which the Hot-Phenol method is a most frequently used, regardless to its cancerous and poisonous nature. In contrary to it is the methanol-chloroform method which is economical, quick and doesn't need phenol which renders it safer than Hot-Phenol method of LPS extraction. The presence of contaminating substances such as capsular polysaccharide, nucleic acids and outer membrane proteins, which are introduced to the final purified LPS during extraction and purification are the main disadvantages of some proposed protocols which hinder its reliable application in most downstream immunological and biological experiments. Thus it becomes necessary to eliminate these contaminants in order to fully exploit the characteristics and functions of LPS. Therefore, the present study was aimed to evaluate the purity and functionality of the isolated LPS from S. typhimurium (MTCC 98) by comparing the common methods of LPS extraction.

\section{Materials and Methods}

\section{Extraction of lipopolysachharide (LPS) by chloroform-methanol method}

Lipopolysachharide (LPS) was extracted by Chloroform-methanol method as per (Mirzaei et al., 2011). In brief, 100ml overnight grown broth culture of standard strain of Salmonella typhimurium (MTCC 98) was centrifuged at $3000 \mathrm{rpm}$ at $4^{0} \mathrm{C}$ for 30 minutes. The supernatant was discarded and the pellet was re-suspended in two $\mathrm{ml}$ of $95 \%$ alcohol by vortexing and then was centrifuged for $10 \mathrm{~min}$ at $2000 \mathrm{rpm}$. The step was repeated four times. Finally the supernatant was discarded and pellet was dried by placing the tube inside hood to completely evaporate alcohol. The dried pellet was re-suspended in one $\mathrm{ml}$ of 10
$\%$ EDTA (quantity sufficient to dissolve a pellet) and was sonicated for $15 \mathrm{~min}$. One $\mathrm{ml}$ of saturated methanol/chloroform (1:2 ratios) was added to bacterium- EDTA solution. The tube lid was covered by paraffin and kept on shaker for two hours following $10 \mathrm{~min}$ centrifugation at $2000 \mathrm{rpm}$. Three layers were formed; methanol, left biomass including cell lysate and chloroform layer from top to bottom. The biomass layer with cell lysate was discarded and chloroform and methanol layers were separated and poured into $50 \mathrm{ml}$ glass beaker to permit complete and quick evaporation of methanol and chloroform layers. The dried pellet thus obtained was LPS. LPS pellet was weighed and reconstituted in sterilized PBS (quantity enough to dissolve a pellet completely) and stored at $-20^{\circ} \mathrm{C}$ until further used.

Extraction of Lipopolysachharide (LPS) by proteinase $\mathrm{K}$ digested, hot phenol-water extraction method

Extraction protocol of (Apicella, 2002; Rezania et al., 2011) was followed. Briefly, a total of $100 \mathrm{ml}$ growth of standard strain Salmonella typhimurium (MTCC 98) was boiled at $100^{\circ} \mathrm{C}$ for two hours in water bath to kill the bacteria and cooled at room temperature. The suspension culture was centrifuged at $10,000 \mathrm{rpm}$ for $15 \mathrm{~min}$. Supernatant was discarded and the pellet was washed twice in sterilized PBS $(\mathrm{pH} 7.2)$ and then suspended in $15 \mathrm{ml}$ of $10 \mathrm{mM}$ Tris-Cl buffer ( $\mathrm{pH}$ 8.0) containing 2 per cent Sodium Dodecyl Sulphate, 4 per cent 2mercaptoethanol and $2 \mathrm{mM} \quad \mathrm{MgCl}_{2}$. The mixture was vortexed and placed in water bath at $65^{\circ} \mathrm{C}$ to solubilise the bacterial cells. The solution was transferred into a $50 \mathrm{ml}$ test tube to which one ml of Proteinase K (@100 $\mu \mathrm{g} / \mathrm{ml})$ was added. The solution was incubated at $65^{\circ} \mathrm{C}$ in water bath for one hour and followed by overnight incubation at $37^{\circ} \mathrm{C}$. Two $\mathrm{ml}$ of $3 \mathrm{M}$ sodium acetate was added to 
cell suspension and mixed thoroughly to enhance LPS precipitation by ethanol. $40 \mathrm{ml}$ of cold absolute ethanol was added to the cell suspension and allowed to precipitate overnight at $-20^{\circ} \mathrm{C}$. The mixture was centrifuged at $4000 \mathrm{rpm}$ for $15 \mathrm{~min}$ and discarded supernatant. Deposits were dissolved in $9 \mathrm{ml}$ of sterilized distilled water and to which one $\mathrm{ml}$ of $3 \mathrm{M}$ sodium acetate was added and vortexed. Further $20 \mathrm{ml}$ of cold absolute ethanol was added and vortexed the mixture again. The suspension was allowed to precipitate overnight at $-20^{\circ} \mathrm{C}$ to remove residual SDS from LPS preparation. After the final centrifugation, precipitate was suspended in $9 \mathrm{ml}$ of $10 \mathrm{mM}$ Tris-Cl (pH 7.4). The final step was a phenol extraction of LPS. To assure the removal of all residual protein contamination, an equal volume of hot (65$\left.70^{\circ} \mathrm{C}\right) 90$ per cent phenol was added to the mixture followed by vigorous shaking at 65 $70^{\circ} \mathrm{C}$ for $15 \mathrm{~min}$. and quickly cooling it to $4^{0} \mathrm{C}$ in an ice bath. The cooled mixture was centrifuged at $6000 \mathrm{rpm}$ for $15 \mathrm{~min}$. and the aqueous top layer was removed and reextracted the phenol layer with an equal volume of distilled water. Sample was heated again to $65^{\circ} \mathrm{C}$ for $15 \mathrm{~min}$ and then placed in ice water. After final centrifugation at 6000 rpm for $5 \mathrm{~min}$, the top aqueous layer was added to the first aqueous extraction and dialysed against multiple changes of Triple distilled water over 2 days and the bottom phenol layer was discarded. After dialysis, the LPS was lyophilized to get powder and stored at $-20^{\circ} \mathrm{C}$ till further use.

\section{Sodium Dodecylsulphate Polyacrylamide Gel Electrophoresis (SDS-PAGE) profiles of the extracted antigens}

In order to characterize the extracted LPSs, they were subjected to SDS-PAGE followed by silver staining and Coomassie blue staining. Polyacrylamide slab gel $(12.5 \%)$ added with 0.1 per cent SDS was used for the test. Briefly the LPSs were mixed separately with the sample buffer (5X) at the rate of $4: 1$ and kept in boiling water bath for $3 \mathrm{~min}$ before loading the gel. About four $\mu 1(80 \mu \mathrm{gm})$ of the LPS was loaded in a well. The gel was run at $40 \mathrm{~V}$ till (stacking gel) and further at 90 $\mathrm{V}$ (in separating gel). The dye-front was noted for migration and completion of run.

\section{Silver staining technique}

LPS was visualization by silver staining technique. The gel was put in fixation for overnight. Both the gels were then subjected to thrice washing with 50 per cent ethanol solution for 20 minutes each. Further, the gels were washed thrice (20 seconds each) in DW and subsequently placed in 0.2 per cent silver nitrate solution for 20 minutes. There after rinsing twice with DW for $20 \mathrm{sec}$ each. The development of reaction for both the gels were stopped by treating with ample of distilled water. The purity of extracted LPS was evaluated by both Silver and Coomassie blue staining of SDS-PAGE gel.

\section{Coomassie brillient blue staining technique}

The SDS-PAGE gels were placed in Coomassie brilliant blue $(0.25 \%)$ staining solution for $10-12 \mathrm{hrs}$ and then transferred to the de-staining solution for 6-7hrs with frequent changes of de-staining solution.

\section{Pyrogen assay}

The efficacy of the purified LPS was tested by rabbit pyrogen assay. The experiment was conducted as per by (Razania et al., 2011; Mirzaei et al., 2011) with slight modification wherein rabbit weighing $2-2.5 \mathrm{Kg}$ was fasted $12 \mathrm{hrs}$ before an experiment. The rectal temperature of rabbit before injecting LPS was recorded after which $25 \mu \mathrm{g} / \mathrm{kg}$ of body weight of purified LPS in sterilized PBS (one $\mathrm{ml}$ ) was injected to rabbit intravenously 
through marginal ear vein. Simultaneously only sterile PBS was injected (one $\mathrm{ml}$ ) in control rabbit. Rectal temperatures were monitored before injection and after every one hour interval until 4th hour of pyrogen administration. The rise in body temperatures by $1-2^{0} \mathrm{C}$ was considered as positive test.

\section{Results and Discussion}

Extraction and purification of Lipopolysaccharide (LPS)

The amount of Lipopolysaccharide (LPS) obtained by Proteinase K-hot phenol-water method was $464 \mathrm{mg}$ whereas that obtained by Chloroform-methanol methodwas $6.69 \mathrm{mg}$.

\section{Sodium-dodecyl sulphate polyacrylamide gel electrophoresis (SDS-PAGE) characterization of lipopolysaccharide (LPS)}

Lipopolysaccharide extracted by Proteinase K-hot phenol-water method revealed typical ladder pattern on silver staining(Fig. 1); further the Coomassie brilliant blue staining confirmed the purity as no protein contamination was observed (Fig. 3), whereas; the LPS extracted by methanolchloroform method did not show any ladder pattern (Fig. 2) and revealed light protein contamination(Fig.3).

\section{Pyrogen assay of purified LPS}

The rabbit pyrogen assay recorded rise in rectal temperature to the tune of $1.5^{\circ} \mathrm{C}$ with Proteinase K-hot phenol-water extracted LPS while the methanol-chloroform extracted LPS was found to elevate temperature by $1^{0} \mathrm{C}$ after three hours of injection.

Several techniques have been introduce in the past for extraction and purification of lipopolysaccharide from Gram negative bacteria, some of them are cumbersome and carcinogenic while some are simple, costeffective, yields high purity end product (Perdomo et al., 2006; Eidhin and Mounton, 1993; Galanos et al., 1969; Nurminen and Vaara, 1996; Apicella, 2002; Razania et al., 2011).

Fig. 1. Ladder Pattern of LPS extracted by hot phenol-water method 


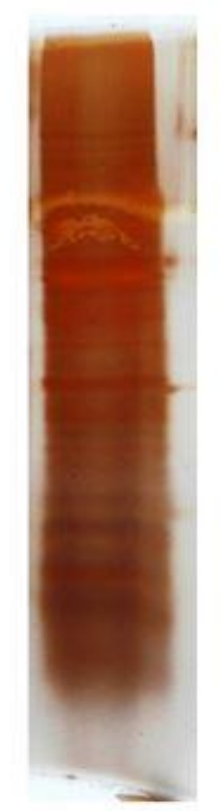

Fig. 2. Pattern of LPS extracted by chloroformmethanol method

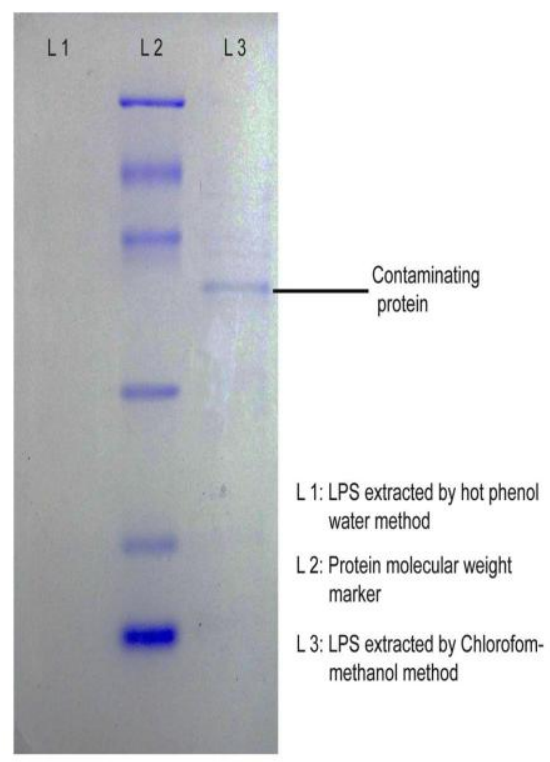

Fig.3. Comassie blue staining of LPS

Presence of contaminating substances in purified LPS hamper its usefulness in downstream applications, therefore, a time reliable and practical approach for isolation of contamination free LPS is necessary. Proteinase $\mathrm{K}$ mediated bacterial protein digestion followed by nuclease elimination of contaminating RNA and DNA and phenolwater extraction method results in highly pure LPS free of protein and nucleic acids (Apicella, 2002; Razania et al., 2011). Proteinase K- hot phenol-water extraction 
method yielded pure LPS devoid of any protein contamination could be due to the enzyme treatment allowing early elimination of contaminating components which considerably enhanced purity in the next steps .Furthermore, hot phenol-mediated extraction subsequently might have resulted in elimination of residual enzymes (Razania et al., 2011). As these steps were missing in methanol-chloroform method might have led to the presence of some impurity. The results of silver staining clearly showed a typical ladder pattern of LPS obtained by Proteinase $\mathrm{K}$, hot phenol-water method which is the characteristics of smooth type of Gram negative bacteria due to the carbohydrate chain length variation of the $\mathrm{O}$-antigen portion. LPS can be classified as either smooth or rough type based on the presence or absence of ladder like structure (Kido et al., 1990; Hitchcock and Brown, 1983; Razania et al., 2011). The result of coomassie blue staining revealed absence of contaminating bacterial proteins from Proteinase K, hot phenol-water LPS suggesting the effectiveness of protein elimination by proteinase-K treatment.

The rabbit pyrogen assay recorded rise in rectal temperature by both the LPSs to the tune of $1.5^{0} \mathrm{C}$ with Proteinase $\mathrm{K}$, hot phenolwater extracted LPS and by $1{ }^{0} \mathrm{C}$ with the methanol-chloroform extracted LPS confirmed the functionality and pyrogenic nature of the endotoxin.

Considering the results of present investigation it was concluded that the, extraction of LPS by methanol-chloroform method was much easy, less expensive and safer but lacks purity, whereas Proteinase-Khot-phenol-water method was tedious, needed meticulous handling of phenol but yielded LPS of high purity which ensures its reliability in downstream application.

\section{Ethical approval}

Experiments have been carried out as per the guidelines laid down by the Institutional Ethical Committee and in accordance with local laws and regulations

\section{Author's contribution}

DGK M.V. Sc Student conducted the work. NNZ and SPC guided and supervised the research work. WK edited and selected photographs needed for the work. SVS and ARP participated in analysis of samples. NNZ, ICAR and University financially supported the present work.

\section{Acknowledgement}

Authors are thankful to Associate Dean, Nagpur Veterinary College, Nagpur for providing the facilities to conduct research, Indian Council of Agricultural Research, New Delhi for financial support for study.

Competing interest: The authors declare that they have no competing interests.

\section{References}

Apicella, M.A. 2000. Isolation and characterization of lipopolysaccharides. In: Evans TJ (eds). Methods in Molecular Medicine (Vol. 431 Bacterial pathogenesis), Totawa: Humana press; 13-25.

Eidhin, D.N. and C. Mounton. 1993. A rapid method for preparationof rough and smooth lipopolysaccharde frombacteroides, Porphyromonas and Prevotella. FEMS Microbiol. Lett., 110(2): 133-38.

Galanos, C., O. Luderitz and O. Westphal, 1969. A new methodfor the extraction of $\mathrm{R}$ lipopolysaccharide. Eur J. Biochem., 9(2): 245-49. 
Hitchcock, P.J. and T.M. Brown. 1983. Morphological heterogeneity among Salmonella lipopolysaccharides chemotypes in silver stained polyacrylamide gels. J. Bacteriol., 154(1): 269-77.

Kawai, T., and S. Akira. 2010. The role of pattern-recognition receptors in innate immunity: update on toll-like receptors. Nat. Immunol., 11(5): 373-84.

Kido, N., M. Ohta and N. Kato. 1990. Detection of lipopolysaccharides by ethidium bromide staining after sodiumdodecylsulfate-polyacrylamide gel electrophoresis. J. Bacteriol., 172(2): 1145-47.

Luderitz, O., C. Galanos, V. Lehmann, M. Nurminen, E.T. Rietschel, G. Rosenfelder, et al. 1973. Lipid A: Chemical structure and biological activity. J. Infect. Dis., 128(1): 17-29.

Mirzaei, A., M. Hedayati, H.R.A. Ashtiani, M. Rahbar and H. Rastgar, 2011. A simple method for non-phenolic extraction of lipopolysaccharide from
Salmonella typhimurium and Salmonella enteritidis with high purity and pyrogenicity in rat. Scientif. Res. Essays, 6(5): 1101.

Nurminen, M. and M. Vaara. 1996. Methanol extracts LPSfrom deep rough bacteria. Biochem. Biophys. Res. Commun., 219(2): 441-44.

Perdomo, R., and V. Montero. 2006. Purification of E.coli 055:B5 lipopolysaccharides by size exclusion chromatography.

Biotecnología Aplicada, 23(2): 124-29.

Prescott, L., J. Harley and D. Klein, 2002. Microbiology. 5th ed. The McGraw Hill. pp. 58-150

Rezania, S., N. Amirmozaffari, B. Tabarraei, M. Jeddi-Tehrani, O. Zarei, R. Alizadeh, F. Masjedian andA. H. Zarnani. 2011. Extraction, purification and Characterization of Lipopolysaccharide from Escherichia coli and Salmonella typhi. Avicenna J. Med. Biotech., 3: 1.

\section{How to cite this article:}

Kalambhe, D.G., N.N. Zade and Chaudhari, S.P. 2017. Evaluation of Two Different Lipopolysaccharide Extraction Methods for Purity and Functionality of LPS. Int.J.Curr.Microbiol.App.Sci. 6(3): 1296-1302. doi: https://doi.org/10.20546/ijcmas.2017.603.150 